Published in final edited form as:

Arch Neurol. 2007 March ; 64(3): 392-398.

\title{
Measures of adiposity and dementia risk in the elderly
}

\author{
Jose A. Luchsinger, MD ${ }^{1,3,6}$, Bindu Patel, MPH ${ }^{1}$, Ming-Xin Tang, PhD ${ }^{1,5}$, Nicole Schupf, \\ PhD $^{1,2,6}$, and Richard Mayeux, MD ${ }^{1,2,4,6,7}$ \\ 1 Taub Institute for Research of Alzheimer's Disease and the Aging Brain, Columbia University, \\ New York, NY. \\ 2 Gertrude H. Sergievsky Center, Columbia University, New York, NY. \\ 3 Division of General Medicine, Department of Medicine, Columbia University College of Physicians \\ and Surgeons, New York, NY.
}

4 Department of Neurology, Columbia University College of Physicians and Surgeons, New York, NY.

5 Department of Biostatistics, Joseph P. Mailman School of Public Health, Columbia University, New York, NY.

6 Department of Epidemiology, Joseph P. Mailman School of Public Health, Columbia University, New York, NY.

7 Department of Psychiatry, Columbia University College of Physicians and Surgeons, New York, NY.

\section{Abstract}

Background-Studies relating adiposity to dementia are conflicting. We explored the associations of body mass index (BMI) waist circumference (WC), and weight change to dementia, probable Alzheimer's disease (AD), and dementia associated with stroke (DAS).

Methods-Persons without dementia were followed for 5 years; 893 persons had BMI, 907 persons had WC, and 709 persons had a second weight measurement. Dementia was ascertained using standard methods. Cox regression was used for analyses using follow-up as time-to-event, adjusting for demographics, and APOE- 24 .

Results-Compared to persons in the first quartile of BMI, persons in the third quartile had a lower dementia and AD risk, and persons in the second quartile had a lower DAS risk. The association between BMI and dementia resembled a U-shape in those $<76$ years, while dementia risk decreased with higher BMI in those $\geq 76$ years. The $4^{\text {th }}$ quartile of WC was related to a higher DAS risk in the whole sample, and to dementia and $\mathrm{AD}$ in persons $<76$ years. Weight loss was related to a higher dementia and DAS risk, and weight gain was related to a higher DAS risk only.

Conclusions-The prospective association between adiposity and dementia differs depending on the anthropometric measure used and is modified by age. This may explain previous conflicting reports.

Correspondence/Requests for reprints: José A. Luchsinger, MD, 630 West $168^{\text {th }}$ St., PH9E-105, New York, NY 10032, Telephone: 212-3054730, Fax: 212-3059349, E-mail: ja194@ columbia.edu.

Support for this work was provided by grants from the National Institutes of Health AG07232, AG07702, 1K08AG20856-01, RR00645, from the Charles S. Robertson Memorial Gift for research on Alzheimer's disease, from the Blanchette Hooker Rockefeller Foundation, and from the New York City Council Speaker's fund for Public Health Research 


\section{INTRODUCTION}

Dementia prevalence may quadruple by $2047^{1}$. High adiposity, hyperinsulinemia, and diabetes are increasing worldwide ${ }^{2-5}$. High adiposity predicts hyperinsulinemia and diabetes 6 , putative dementia risk factors $7-12$. The few studies exploring the association between adiposity, measured by body mass index (BMI), and dementia in the elderly were conflicting 13-15. Reasons for this may include that waist circumference (WC) may be a better adiposity marker than $\mathrm{BMI}^{16}$, that the association between high BMI and outcomes is attenuated with age $^{17}$, and that low BMI is a marker of weight loss, frailty and pre-clinical dementia. We hypothesized that higher adiposity is related to higher dementia risk, and that this relation is attenuated by age. We examined the prospective associations of BMI, WC, and weight change to dementia in the elderly, and explored their modification by age.

\section{METHODS}

\section{Participants and Setting}

Participants were enrolled in a longitudinal study by random sampling of Medicare recipients 65 years or older residing in northern Manhattan (Washington Heights, Hamilton Heights, Inwood) ${ }^{18}$. Each participant underwent an in-person interview of general health and function at the time of study entry followed by a standard assessment, including medical history, physical, neurological, and neuropsychological examination ${ }^{19}$. Baseline data were collected from 1992 through 1994. Follow-up data were collected at intervals of approximately 18 months. The institutional review board of Columbia-Presbyterian Medical Center approved this study.

Anthropometric measures were taken at first follow-up, when 1,484 (69.8\%) persons were available; 1,372 (92.4\%) of those had anthropometric measures; 255 (17.2\%) were excluded due to prevalent dementia. Among those with follow-up after the first follow-up examination, $893(60.2 \%)$ persons had information on BMI, and 907 (61.1\%) persons had WC; 709 (47.8\%) had a second weight measurement at the subsequent examination with additional follow-up, and were part of longitudinal analyses with weight change.

\section{Body Mass Index, Waist Circumference, and Weight Change}

BMI was calculated as weight in kilograms divided by height in meters-squared $\left(\mathrm{kg} / \mathrm{m}^{2}\right)$. With the participant standing, body weight was measured to the nearest $0.1 \mathrm{~kg}$ with a balance scale, and height was measured without shoes to the nearest $0.5 \mathrm{~cm}$. WC represents excess fat in the abdomen out of proportion to total body fat and is an independent predictor of vascular risk factors and morbidity ${ }^{16}$. WC was measured at the level of the iliac crest at minimal inspiration to the closest $0.1 \mathrm{~cm}$. BMI and $\mathrm{WC}$ were used as continuous variables and categorized by quartiles. We did not use National Heart Blood and Lung Institute criteria for BMI because its value in the elderly is questionable ${ }^{20}$. We calculated the yearly rate of weight change between the first and second follow-up interval and classified persons in 3 groups: 1) weight loss (> 1 $\mathrm{kg}$; 2) stable weight (1 kg of loss to $1 \mathrm{~kg}$ of gain); 3 ) weight gain (>1 kg).

\section{Diagnosis of Dementia}

Dementia diagnosis was made by consensus of neurologists, psychiatrists, and neuropsychologists. Dementia diagnosis was based on DSM-IV criteria 21 and required evidence of cognitive deficit and evidence of impairment in social or occupational function (Clinical Dementia Rating of 1 or more) ${ }^{22}$. AD diagnosis was based on NINCDS-ADRDA criteria $^{23}$. A diagnosis of probable AD was made when dementia could not be explained by other disorders. A diagnosis of possible $\mathrm{AD}$ was made when the most likely cause of dementia was $\mathrm{AD}$, but there were other disorders that could contribute such as stroke and Parkinson's 
disease. A diagnosis of vascular dementia was made when it started within 3 months of the stroke and its local effects were thought to be the primary cause. Brain imaging was available in $85 \%$ of stroke cases; in the remainder, World Health Organization stroke criteria were used 24 . We conducted analyses with three outcomes, all-cause-dementia, probable $\mathrm{AD}$, and dementia associated with stroke (DAS) which included vascular dementia and possible AD with stroke. The rationale for these outcomes is that obesity is related to vascular disease and stroke ${ }^{25}$, and we sought to distinguish the association of adiposity to dementias with and without a vascular component.

\section{Covariates}

Diabetes mellitus, hypertension, heart disease and smoking were defined by self report. Heart disease included a history of atrial fibrillation, other arrhythmias, congestive heart failure, myocardial infarction, and angina pectoris. Smoking was sub-classified into current and past smoking. Fasting plasma cholesterol and triglycerides were determined at first follow-up using standard enzymatic techniques. High-density lipoprotein (HDL) cholesterol levels were determined after precipitation of apolipoprotein B containing lipoproteins with phosphotungstic acid ${ }^{26}$. Low-density lipoprotein (LDL) cholesterol was recalculated using the formula of Friedewald ${ }^{27}$. APOE genotypes were determined as described by Hixson and Vernier 28,29 . We classified APOE- 24 as present (homozygeous or heterozygeous) or absent.

\section{Statistical Methods}

Bivariate analyses compared variables among BMI quartiles. Continuous variables were compared using analysis of variance (ANOVA), and categorical variables using chi-square 30. First, global tests for all quartiles were made. If significant differences were found, further comparisons were made for continuous variables using Scheffe's multiple-comparison procedure; for categorical variables pair-wise comparisons with the reference category were conducted. An $\alpha=0.05$ was used for all analyses. Proportional hazards models 31 were used in multivariate analyses. The time-to-event variable was time from BMI or WC measurement to incident dementia; individuals who did not develop dementia were censored at last followup. For analyses with weight change the time-to-event variable was time from the second weight measurement to dementia onset. Individuals who developed dementia other than the one if interest were censored at the time of diagnosis. We show the results of multivariate analyses for 2 models: one adjusted for age and gender, and one adjusted also for education, ethnic group, and APOE- $\varepsilon 4$. We adjusted for diabetes, hypertension, LDL, heart disease, stroke, and current smoking in secondary analyses. Because stroke defines DAS it was not used as a covariate in analyses by dementia subtype. These variables, with the exception of smoking, may be caused by higher adiposity 32 , may be in the pathway between adiposity and dementia, and were not included in the main models. We conducted three main analyses relating: 1) BMI to dementia; 2) WC to dementia, and 3) weight change to dementia. The reference in analyses with $\mathrm{BMI}$ and $\mathrm{WC}$ was the first quartile, and in analyses with weight change it was the stable weight group.

Current smoking is associated with higher dementia risk 33 and lower BMI ${ }^{34}$, and we conducted secondary analyses excluding smokers. Lower BMI may be associated to unidentified premorbid conditions, including preclinical dementia 35 , and we conducted secondary analyses excluding individuals with $<18$ months of follow-up. All analyses were conducted using SAS 9.1 for Windows.

\section{RESULTS}

There were 181 incident dementia cases (3.9/100 person-years), 112 AD and 53 DAS, in 4,536 person-years of follow-up (mean $=5.1 \pm 2.6$ years). The mean sample age was $77.0 \pm 5.7$ years, 
69.9\% were women, 31.8\% African American, 45.2\% Hispanic, and 22.9\% White. The mean years of education was $8.8 \pm 4.6$, and $27.9 \%$ had APOE- $\varepsilon 4 ; 18.5 \%$ reported diabetes, $59.6 \%$ hypertension, $25.9 \%$ heart disease, and $11.5 \%$ stroke. The mean LDL was $120.9 \pm 34.9 \mathrm{mg} / \mathrm{dl}$. We compared characteristics among quartiles of BMI (Table 1) using the first as the reference. Persons in the second quartile had a lower proportion of women, higher diabetes prevalence, and lower prevalence of current smoking and stroke. Persons in the third quartile were younger, had higher hypertension and diabetes prevalence, and lower prevalence of current smoking. Persons in the fourth quartile were younger, had a higher proportion of women and AfricanAmericans, a lower proportion of Whites, higher hypertension, diabetes, and heart disease prevalence, and lower prevalence of current smoking.

\section{Relation of body mass index to dementia}

$\mathrm{BMI}$ as a continuous variable was not related to dementia (HR=0.9; 95\% CI: 0.9,1.0), $\mathrm{AD}$ (HR $=0.9 ; 95 \%$ CI: $0.9,1.0)$, or DAS (HR=1.1; 95\% CI: 0.9,1.3) in fully adjusted models.

The third quartile (Table 2), was associated with lower dementia risk compared to the first $(\mathrm{HR}=0.6 ; 95 \% \mathrm{CI}: 0.4,0.9)$ after adjusting for age, gender, education, ethnic group and APOE$\varepsilon 4$. The association between the second quartile and lower dementia risk was close to statistical significance (HR=0.7; 95\% CI: $0.5,1.0 ; \mathrm{p}=0.06$ ). For $\mathrm{AD}$, the third quartile was associated with lower risk (HR=0.5; 95\% CI: 0.3, 0.9). For DAS, the association between the second quartile and lower risk was almost statistically significant (HR=0.4;95\% CI: $0.2,1.0 ; \mathrm{p}=0.06$ ). Inclusion of vascular risk factors in the models did not change the results.

In persons $<76$ years the association between BMI quartiles and dementia resembled a Ushape (Figure 1). The second (HR=0.4;95\% CI: $0.2,0.9$ ) and third (HR= 0.3;95\% CI: $0.1,0.8$ ) quartiles were related to lower risk, while the fourth $(\mathrm{HR}=1.0 ; 95 \%$ CI: $0.4,2.1 ; \mathrm{p}$ for trend $=$ $0.91)$ was similar to the reference. In older people, dementia risk decreased with increasing BMI; this association was almost statistically significant ( $4^{\text {th }}$ quartile HR: 0.6 ; 95\% CI: 0.4,1.1; $\mathrm{p}$ for trend $=0.07$ ). These associations were not modified by gender, and did not change after exclusion of current smokers or persons with short follow-up.

\section{Relation of waist circumference to dementia}

WC as a continuous variable was not associated to dementia (HR $=1.0 ; 95 \% \mathrm{CI}: 0.9,1.0)$; the associations with $\mathrm{AD}$ and DAS were similar. WC quartiles were not related to dementia or $\mathrm{AD}$ (Table 3), but DAS risk was increased for the fourth quartile (HR=2.3; 95\% CI: 1.0, 5.1; p for trend $=0.02$ ) after adjusting for age, gender, education, ethnic group and APOE- $\varepsilon 4$. The results were virtually unchanged after adjusting for vascular risk factors. In younger elderly the fourth quartile was related to higher dementia $(\mathrm{HR}=2.3 ; 95 \% \mathrm{CI}=0.9,5.8 ; \mathrm{p}$ for trend $=0.03)$, and $\mathrm{AD}$ risk $(\mathrm{HR}=5.1 ; 95 \% \mathrm{CI}=1.0,26.4 ; \mathrm{p}$ for trend $=0.04)$, but in older persons the fourth quartile was not related to dementia $(\mathrm{HR}=1.0 ; 95 \% \mathrm{CI}=0.6,1.7 ; \mathrm{p}$ for trend $=0.93)$ or $\mathrm{AD}(\mathrm{HR}=0.8 ; 95 \%$ $\mathrm{CI}=0.4,1.8 ; \mathrm{p}$ for trend $=0.37$ ) (Figure 2).

\section{Relation of weight change to dementia}

We had one follow-up weight measurement in 709 persons out of 713 persons without dementia eligible for follow-up. The mean interval between weight measurements was $1.3 \pm 0.6$ years. The mean weight change was $-0.5 \pm 3.4 \mathrm{~kg}$. The mean follow-up after the second weight measurement was $4.7 \pm 2.1$ years. Weight change as a continuous variable was associated with decreased dementia risk ( $\mathrm{HR}=0.9 ; 95 \% \mathrm{CI}$ : 0.8-0.9). In analyses categorizing with changes as loss, stable, or gain, persons with weight loss had a higher dementia risk (Table 4) compared to persons with stable weight $(\mathrm{HR}=1.9 ; 95 \% \mathrm{CI}: 1.2,2.9)$ after adjustment for baseline BMI, age, gender, education, ethnic group, and APOE- 4 . This association was strongest for DAS $(\mathrm{HR}=4.9 ; 95 \% \mathrm{CI}: 1.9,12.9)$. DAS risk was also higher in persons who gained weight (HR 
$=2.8 ; 95 \%$ CI: $1.0,7.9)$. The results were unchanged in models with vascular risk factors, and after excluding current smokers and persons with short follow-up. There was no effect modification by age or gender.

We conducted additional analyses exploring different cutoffs for weight change (tertiles, $25^{\text {th }}$ and $75^{\text {th }}$ percentile, $10^{\text {th }}$ and $90^{\text {th }}$ percentiles), and the results were similar.

\section{COMMENT}

The association between adiposity and incident dementia varied with the measure used, the outcome considered, and was modified by age. The only association that clearly resembled a linear pattern (higher risk with higher quartile) was that of WC and DAS. However, the fourth WC quartile was related to a higher dementia and $\mathrm{AD}$ risk in persons $<76$ years, but not in the oldest old. The association of BMI to dementia resembled a U-shape in those < 76 years. Weight loss was associated with a higher dementia risk. This association stronger for DAS, and weight gain was also associated with DAS.

$\mathrm{AD}$ and vascular dementia are the most common forms of dementia ${ }^{37}$. AD is probably caused by brain deposition of amyloid beta ${ }^{38}$, and peripheral hyperinsulinemia may have an important role in its clearance ${ }^{39}$. Vascular risk factors and stroke cause vascular dementia $40-43$, but they may also cause $\mathrm{AD}^{44,45}$. There are conflicting data relating hyperinsulinemia $7,8,46-$ 48 , diabetes $49-52$ and hyperinsulinemia features such as hyperlipidemia 53 and hypertension $53-57$ to a higher risk of cognitive decline and AD. Higher adiposity are related to

hyperinsulinemia, diabetes, hypertension, dyslipidemia, heart disease, and stroke 32,58 . Thus, we hypothesized that high BMI and WC are associated with higher dementia, AD, and DAS risk.

High BMI in middle age is associated with higher dementia risk 59,60 . Higher BMI at ages 70,75 and 79 years also predicts higher dementia risk ${ }^{15}$. However, there have been reports of no association ${ }^{14}$ and of lower BMI related to higher AD risk ${ }^{13}$. These paradoxical findings could be explained by different age groups in different studies; those conducted in middle age show a relation of high BMI to increased dementia risk, while those in older populations are conflicting. The association of high BMI to cardiovascular and general mortality is attenuated in older age groups, and high BMI becomes a predictor of decreased mortality in the oldest old 17. This is possibly due to survival bias and to decreased value of BMI as an adiposity measure in the oldest old. Aging is characterized by lean body mass loss and adipose tissue increase without weight gain that may not be captured by BMI, and traditional adiposity measures are less useful in the elderly 61 . Another potential explanation for paradoxical findings is the possibility of a U-shape association between BMI and dementia as has been reported for other outcomes ${ }^{34}$. Low BMI related to worse outcomes is usually ascribed to conditions associated with weight loss. Higher BMI related to worse outcomes is usually interpreted as evidence of the consequences of high adiposity. The results of our study suggest a U-shape association between BMI and dementia in the younger elderly, while higher BMI is related to lower dementia risk in the oldest old. It is possible that persons with the lowest BMI lost weight due to pre-morbid dementia. It is also possible that low BMI is the consequence of hyperinsulinemia, which precede weight loss 62 and is related to higher dementia risk 7,8 .

WC has been proposed as a better adiposity measure in the elderly than BMI $16,61,63$. We found that higher WC was associated to higher DAS risk for all age groups. The association between vascular risk factors and dementia is clearly stronger for DAS compared to $\mathrm{AD}^{44}$, and this may explain why WC only predicted DAS in the whole sample. However, higher WC was associated with higher dementia and $\mathrm{AD}$ risk in younger elderly, consistent with the notion that adiposity measures lose their predictive ability in the oldest old 61 . 
Persons may lose weight prior to dementia diagnosis 14,64 and this has been interpreted as a consequence of the disease rather than a direct cause ${ }^{14}$. We did not have enough data to assess weight change up to dementia diagnosis. We had weights at 2 time points for a sub-sample and explored how weight change predicted dementia prospectively. We found that weight loss predicted higher dementia risk in agreement with previous work. As mentioned previously, this could be a consequence of the dementia process, but could also be the consequence and a marker of hyperinsulinemia ${ }^{64}$, an emerging dementia risk factor ${ }^{7,8}$. We also found that weight gain predicted higher DAS risk, which has not been reported to the best of our knowledge. This could reflect increase in vascular risk factors with weight gain ${ }^{32}$, but could also be a consequence of cardiovascular disease, such as heart failure causing edema and weight gain 65 .

We must consider the possibility that confounding, chance or bias explain the results of this study. We conducted analyses excluding current smokers and persons with short follow-up and the results were essentially unchanged. We adjusted for years of education and ethnic group as indices of socioeconomic background without change in our findings, but we cannot rule out residual confounding. The ascertainment of covariates such as smoking were made by selfreport, likely resulting in some misclassification that could have resulted in residual confounding. Another consideration is the fact that we conducted multiple comparisons, including those in stratified analyses. Invocation of multiple comparisons as an explanation of results is a controversial issue ${ }^{66}$, but it is possible that our results could be explained by chance. The most striking results occurred in the stratified analyses. Finding of significant results for some quartiles by chance could lead to identification of patterns that also occurred by chance. Despite the results not being unexpected, and consistent with previous publications in the aging literature, chance due to multiple comparisons is a possibility as an explanation for our findings, and our analyses should be replicated in other samples. The number of persons developing DAS was appreciably smaller than those developing $\mathrm{AD}$, and this could have resulted in chance findings due to sparse data. When interpreting and generalizing the results, it is important to take into account that this study occurred in the context of a cohort study of the elderly with multiple ethnic groups, in an urban setting, with a high prevalence of vascular risk factors. It is a cohort with potential selection biases, particularly because high adiposity is related to increased morbidity and mortality that could have limited participation to persons who were less likely to have this risk factor.

Our study has several strengths. We had comprehensive research procedures for the diagnosis of dementia. We also had measures of BMI and WC, and weight at two time-points, but did not have a weight history prior to inclusion in the cohort. To the best of our knowledge, this is the first study examining the relation between WC and dementia in the elderly.

Our results show that high adiposity may be associated with higher dementia risk, particularly in younger elderly. However, this association could be confounded by low weight and weight loss due to pre-clinical disease and is attenuated in older age groups. This may explain conflicts in previous studies. Our results need to be replicated in other studies. Similar studies are needed with imaging or biomarkers of adipose tissue.

\section{References}

1. Brookmeyer R, Gray S, Kawas C. Projections of Alzheimer's disease in the United States and the public health impact of delaying disease onset. Am J Public Health 1998;88:1337-1342. [PubMed: 9736873]

2. Knowler WC, Narayan KM, Hanson RL, et al. Preventing non-insulin-dependent diabetes. Diabetes 1995;44:483-488. [PubMed: 7729603]

3. Harris MI. Diabetes in America: epidemiology and scope of the problem. Diabetes Care 1998;21 (Suppl 3):C11-14. [PubMed: 9850480] 
4. Harris MI, Flegal KM, Cowie CC, et al. Prevalence of diabetes, impaired fasting glucose, and impaired glucose tolerance in U.S. adults. The Third National Health and Nutrition Examination Survey, 19881994. Diabetes Care 1998;21:518-524. [PubMed: 9571335]

5. Mann J. Stemming the tide of diabetes mellitus. Lancet 2000;356:1454-1455. [PubMed: 11081521]

6. Reaven, GM.; Laws, A. Totowa, New Jersey: Humana Press; 1999. Insulin resistance: the metabolic syndrome X.

7. Luchsinger JA, Tang MX, Shea S, Mayeux R. Hyperinsulinemia and risk of Alzheimer disease. Neurology 2004;63:1187-1192. [PubMed: 15477536]

8. Peila R, Rodriguez BL, White LR, Launer LJ. Fasting insulin and incident dementia in an elderly population of Japanese-American men. Neurology 2004;63:228-233. [PubMed: 15277613]

9. Luchsinger JA, Reitz C, Honig LS, Tang MX, Shea S, Mayeux R. Aggregation of vascular risk factors and risk of incident Alzheimer disease. Neurology 2005;65:545-551. [PubMed: 16116114]

10. Peila R, Rodriguez BL, Launer LJ. Type 2 Diabetes, APOE Gene, and the Risk for Dementia and Related Pathologies: The Honolulu-Asia Aging Study. Diabetes 2002;51:1256-1262. [PubMed: 11916953]

11. Ott A, Stolk RP, van Harskamp F, Pols HA, Hofman A, Breteler MM. Diabetes mellitus and the risk of dementia: The Rotterdam Study. Neurology 1999;53:1937-1942. [PubMed: 10599761]

12. Leibson CL, Rocca WA, Hanson VA, et al. Risk of dementia among persons with diabetes mellitus: a population- based cohort study. Am J Epidemiol 1997;145:301-308. [PubMed: 9054233]

13. Nourhashemi F, Deschamps V, Larrieu S, Letenneur L, Dartigues J-F, Barberger-Gateau P. Body mass index and incidence of dementia: The PAQUID study. Neurology 2003;60:117-119. [PubMed: 12525731]

14. Stewart R, Masaki K, Xue Q-L, et al. A 32-Year Prospective Study of Change in Body Weight and Incident Dementia: The Honolulu-Asia Aging Study. Arch Neurol 2005;62:55-60. [PubMed: 15642850]

15. Gustafson D, Rothenberg E, Blennow K, Steen B, Skoog I. An 18-Year Follow-up of Overweight and Risk of Alzheimer Disease. Arch Intern Med 2003;163:1524-1528. [PubMed: 12860573]

16. Janssen I, Katzmarzyk PT, Ross R. Waist circumference and not body mass index explains obesityrelated health risk. Am J Clin Nutr 2004;79:379-384. [PubMed: 14985210]

17. Stevens J, Cai J, Pamuk ER, Williamson DF, Thun MJ, Wood JL. The effect of age on the association between body-mass index and mortality. New Eng J Med 1998;338:1-7. [PubMed: 9414324]

18. Tang MX, Stern Y, Marder K, et al. The APOE-epsilon4 allele and the risk of Alzheimer disease among African Americans, whites, and Hispanics. JAMA 1998;279:751-755. [PubMed: 9508150]

19. Stern Y, Andrews H, Pittman J, et al. Diagnosis of dementia in a heterogeneous population. Development of a neuropsychological paradigm-based diagnosis of dementia and quantified correction for the effects of education. Arch Neurol 1992;49:453-460. [PubMed: 1580806]

20. Heiat A, Vaccarino V, Krumholz HM. An Evidence-Based Assessment of Federal Guidelines for Overweight and Obesity as They Apply to Elderly Persons. Arch Intern Med 2001;161:1194-1203. [PubMed: 11343442]

21. 4th edition. Washington, D.C.: American Psychiatric Association; 1994. Diagnostic and Statistical manual of mental disorders.

22. Hughes CP, Berg L, Danziger WL, Coben LA, Martin RL. A new clinical scale for the staging of dementia. Br J Psychiatry 1982;140:566-572. [PubMed: 7104545]

23. McKhann G, Drachman D, Folstein M, Katzman R, Price D, Stadlan EM. Clinical diagnosis of Alzheimer's disease: report of the NINCDS-ADRDA Work Group under the auspices of Department of Health and Human Services Task Force on Alzheimer's Disease. Neurology 1984;34:939-944. [PubMed: 6610841]

24. Geneva, Switzerland: World Health Organization; 1993. The ICD-10 Classification of mental and behabioral disorders: diagnostic criteria for research.

25. Kurth T, Gaziano JM, Berger K, et al. Body mass index and the risk of stroke in men. Arch Int Med 2002;162:2557-2562. [PubMed: 12456227]

26. Lopes-Virella MF, Stone P, Ellis S, Colwell JA. Cholesterol determination in high-density lipoproteins separated by three different methods. Clin Chem 1977;23:882-884. [PubMed: 192488] 
27. Friedewald WT, Levy RI, Fredrickson DS. Estimation of the concentration of low-density lipoprotein cholesterol in plasma, without use of the preparative ultracentrifuge. Clin Chem 1972;18:499-502. [PubMed: 4337382]

28. Hixson JE, Vernier DT. Restriction isotyping of human apolipoprotein E by gene amplification and cleavage with HhaI. J Lipid Res 1990;31:545-548. [PubMed: 2341813]

29. Mayeux R, Ottman R, Maestre G, et al. Synergistic effects of traumatic head injury and apolipoproteinepsilon 4 in patients with Alzheimer's disease. Neurology 1995;45:555-557. [PubMed: 7898715]

30. Fleiss, JL. Second ed. Joseph Wiley and Sons; 1981. Statistical methods for rates and proportions.

31. Cox, DR.; Oakes, D. London: Chapman \& Hall; 1984. Analysis of survival data.

32. Pi-Sunyer FX. The Obesity Epidemic: Pathophysiology and Consequences of Obesity. Obes Res 2002;10:97S-104. [PubMed: 12490658]

33. Ott A, Slooter AJ, Hofman A, et al. Smoking and risk of dementia and Alzheimer's disease in a population-based cohort study: the Rotterdam Study. Lancet 1998;351:1840-1843. [PubMed: 9652667]

34. Allison DB, Faith MS, Heo M, Kotler DP. Hypothesis concerning the U-shaped relation between body mass index and mortality. Am J Epidemiol 1997;146:339-349. [PubMed: 9270413]

35. Cronin-Stubbs D, Beckett LA, Scherr PA, et al. Weight loss in people with Alzheimer's disease: a prospective population based analysis. BMJ 1997;314:178-179. [PubMed: 9022430]

36. Strawbridge WJ, Wallhagen MI, Shema SJ. New NHLBI clinical guidelines for obesity and overweight: will they promote health? Am J Pub Health 2000;90:340-343. [PubMed: 10705849]

37. Ritchie K, Lovestone S. The dementias. Lancet 2002;360:1759-1766. [PubMed: 12480441]

38. Selkoe DJ. The origins of Alzheimer disease: a is for amyloid. JAMA 2000;283:1615-1617. [PubMed: 10735401]

39. Farris W, Mansourian S, Chang Y, et al. Insulin-degrading enzyme regulates the levels of insulin, amyloid beta-protein, and the beta-amyloid precursor protein intracellular domain in vivo. Proc Natl Acad Sci USA 2003;100:4162-4167. [PubMed: 12634421]

40. Barba R, Martinez-Espinosa S, Rodriguez-Garcia E, Pondal M, Vivancos J, Del Ser T. Poststroke dementia : clinical features and risk factors. Stroke 2000;31:1494-1501. [PubMed: 10884443]

41. DeCarli C. The role of cerebrovascular disease in dementia. Neurologist 2003;9:123-136. [PubMed: 12808409]

42. Gorelick PB. Status of risk factors for dementia associated with stroke. Stroke 1997;28:459-463. [PubMed: 9040707]

43. Hebert R, Lindsay J, Verreault R, Rockwood K, Hill G, Dubois MF. Vascular dementia : incidence and risk factors in the Canadian study of health and aging. Stroke 2000;31:1487-1493. [PubMed: 10884442]

44. Luchsinger J, Mayeux R. Cardiovascular risk factors and Alzheimer's disease. Curr Atheroscler Rep 2004;6:261-266. [PubMed: 15191699]

45. Breteler MM. Vascular risk factors for Alzheimer's disease: an epidemiologic perspective. Neurobiol Aging 2000;21:153-160. [PubMed: 10867200]

46. Curb JD, Rodriguez BL, Abbott RD, et al. Longitudinal association of vascular and Alzheimer's dementias, diabetes, and glucose tolerance. Neurology 1999;52:971-975. [PubMed: 10102414]

47. Kalmijn S, Foley D, White L, et al. Metabolic cardiovascular syndrome and risk of dementia in Japanese- American elderly men. The Honolulu-Asia aging study. Arterioscler Thromb Vasc Biol 2000;20:2255-2260. [PubMed: 11031212]

48. Carantoni M, Zuliani G, Munari MR, D'Elia K, Palmieri E, Fellin R. Alzheimer disease and vascular dementia: relationships with fasting glucose and insulin levels. Dement Geriatr Cogn Disord 2000;11:176-180. [PubMed: 10765049]

49. Ott A, Stolk RP, Hofman A, van Harskamp F, Grobbee DE, Breteler MM. Association of diabetes mellitus and dementia: the Rotterdam Study. Diabetologia 1996;39:1392-1397. [PubMed: 8933010]

50. Gregg EW, Beckles GL, Williamson DF, et al. Diabetes and physical disability among older U.S. adults. Diabetes Care 2000;23:1272-1277. [PubMed: 10977018]

51. Vanhanen M, Kuusisto J, Koivisto K, et al. Type-2 diabetes and cognitive function in a non-demented population. Acta Neurol Scand 1999;100:97-101. [PubMed: 10442450] 
52. Janson J, Laedtke T, Parisi JE, O'Brien P, Petersen RC, Butler PC. Increased Risk of Type 2 Diabetes in Alzheimer Disease. Diabetes 2004;53:474-481. [PubMed: 14747300]

53. Kivipelto M, Laakso MP, Tuomilehto J, Nissinen A, Soininen H. Hypertension and hypercholesterolaemia as risk factors for Alzheimer's disease: potential for pharmacological intervention. CNS Drugs 2002;16:435-444. [PubMed: 12056919]

54. Kivipelto M, Helkala EL, Hanninen T, et al. Midlife vascular risk factors and late-life mild cognitive impairment: A population-based study. Neurology 2001;56:1683-1689. [PubMed: 11425934]

55. Posner HB, Tang MX, Luchsinger J, Lantigua R, Stern Y, Mayeux R. The relationship of hypertension in the elderly to AD, vascular dementia, and cognitive function. Neurology 2002;58:1175-1181. [PubMed: 11971083]

56. Skoog I, Gustafson D. Hypertension, hypertension-clustering factors and Alzheimer's disease. Neurological Research 2003;25:675-680. [PubMed: 14503023]

57. Skoog I, Lernfelt B, Landahl S, et al. 15-year longitudinal study of blood pressure and dementia. Lancet 1996;347:1141-1145. [PubMed: 8609748]

58. Reaven GM. Insulin resistance, type 2 diabetes mellitus, and cardiovascular disease: the end of the beginning. Circulation 2005;112:3030-3032. [PubMed: 16286599]

59. Whitmer RA, Gunderson EP, Barrett-Connor E, Quesenberry CP Jr, Yaffe K. Obesity in middle age and future risk of dementia: a 27 year longitudinal population based study. BMJ 2005bmj. 38446.466238.E466230.

60. Kivipelto M, Ngandu T, Fratiglioni L, et al. Obesity and vascular risk factors at midlife and the risk of dementia and Alzheimer disease. Arch Neurol 2005;62:1556-1560. [PubMed: 16216938]

61. Stevens J, Cai J, Juhaeri, Thun MJ, Williamson DF, Wood JL. Consequences of the use of different measures of effect to determine the impact of age on the association between obesity and mortality. Am J Epidemiol 1999;150:399-407. [PubMed: 10453816]

62. Wedick NM, Mayer-Davis EJ, Wingard DL, Addy CL, Barrett-Connor E. Insulin Resistance Precedes Weight Loss in Adults without Diabetes : The Rancho Bernardo Study. Am. J. Epidemiol 2001;153:1199-1205.

63. Visscher TL, Seidell JC, Molarius A, van der Kuip D, Hofman A, Witteman JC. A comparison of body mass index, waist-hip ratio and waist circumference as predictors of all-cause mortality among the elderly: the Rotterdam study. Int J Obes 2001;25:1730-1735.

64. Buchman AS, Wilson RS, Bienias JL, Shah RC, Evans DA, Bennett DA. Change in body mass index and risk of incident Alzheimer disease. Neurology 2005;65:892-897. [PubMed: 16186530]

65. Schiff GD, Fung S, Speroff T, McNutt RA. Decompensated heart failure: symptoms, patterns of onset, and contributing factors. Am J Med 2003;114:625-630. [PubMed: 12798449]

66. Rothman KJ. No adjustments are needed for multiple comparisons. Epidemiology 1990;1:43-46. [PubMed: 2081237] 
Arch Neurol (in press)

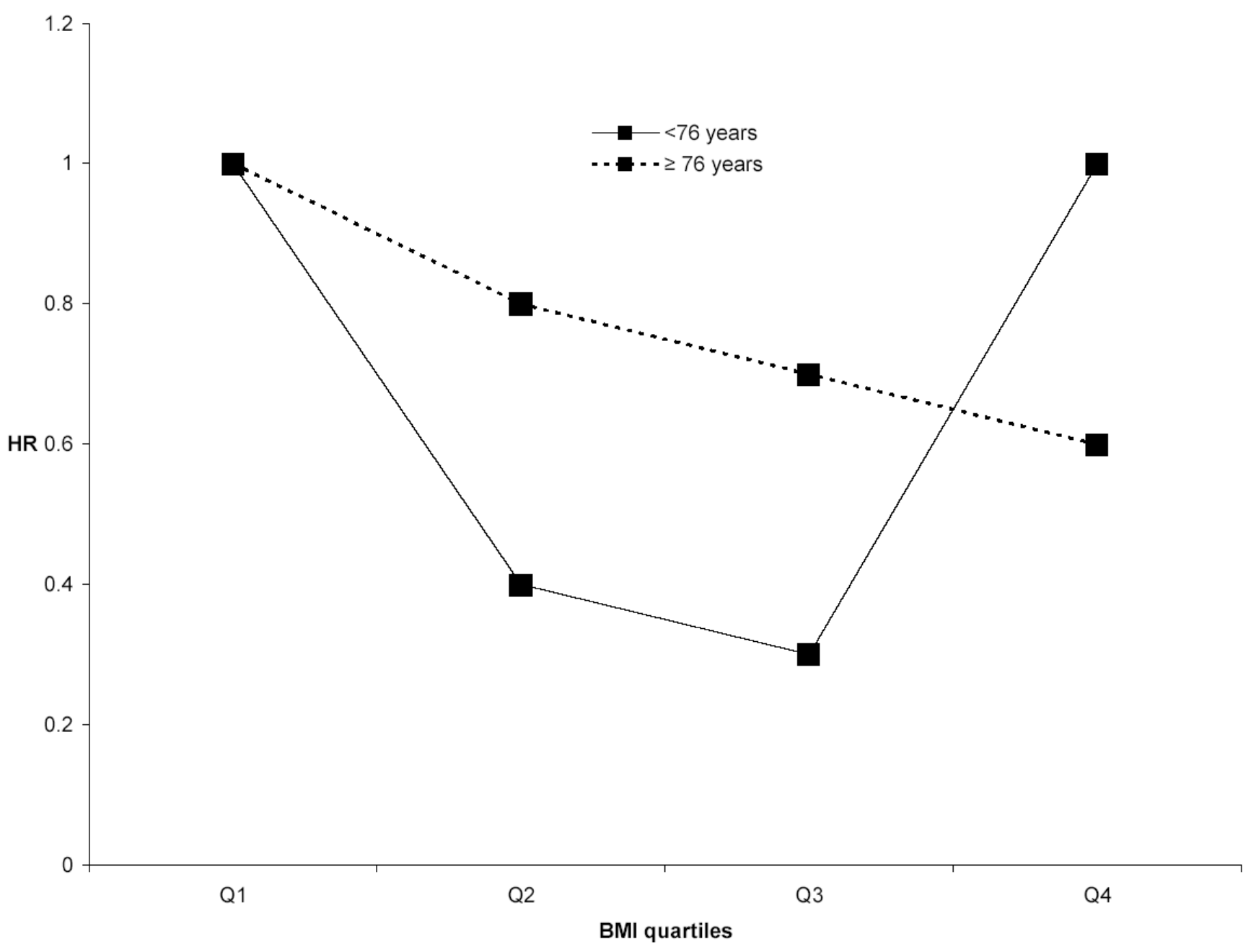

Figure 1.

Hazard ratios (HR) relating quartiles (Q) of body mass index (BMI) to all-cause dementia in persons $<76$ years old and persons $\geq 76$ years old, adjusting for age, sex, years of education, ethnic group, and APOEe4. Only the HR for the $3^{\text {rd }}$ and 4 th quartiles in persons $<76$ years were statistically significant. 
Arch Neurol (in press)

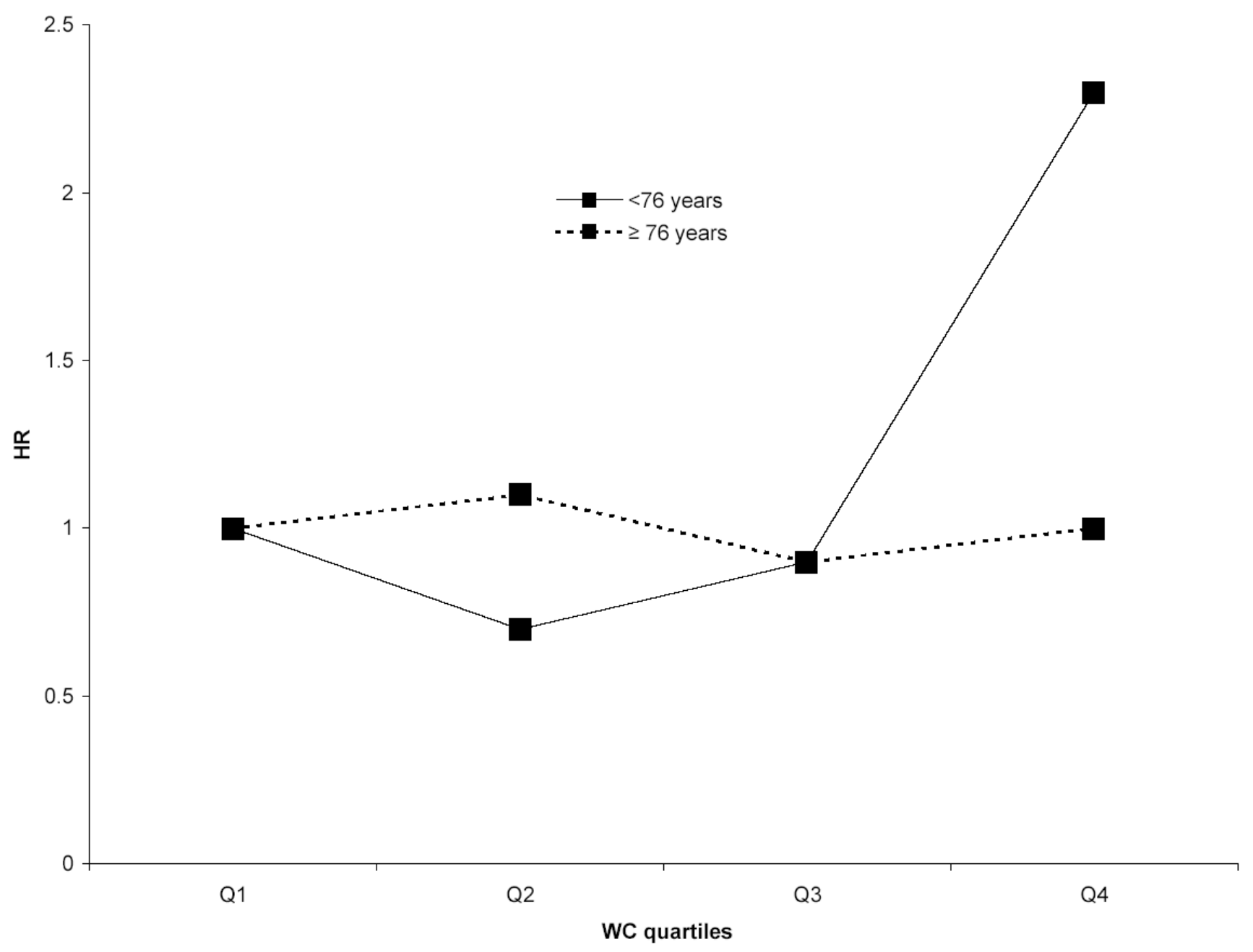

Figure 2.

Hazard ratios (HR) relating quartiles (Q) of waist circumference (WC) to all-cause dementia in persons $<76$ years old and persons $\geq 76$ years old, adjusting for age, sex, years of education, ethnic group, and APOEe 4 . The HR for the $4^{\text {th }} \mathrm{Q}$ of $\mathrm{WC}$ and the $\mathrm{p}$ for trend in persons $<76$ years were statistically significant. 
Table 1

Comparison of relevant characteristics between body mass index (BMI) quartiles. Washington Heights-Inwood Columbia Aging Project, 1992-2003.

\begin{tabular}{|c|c|c|c|c|}
\hline Characteristics & $\begin{array}{c}1 \text { quartile } \\
\mathrm{kg} / \mathrm{m}^{2}\end{array} 223.4$ & $\begin{array}{c}2 \text { quartile } 23.4-26.2 \\
\mathrm{~kg} / \mathrm{m}^{2}\end{array}$ & $\begin{array}{c}3 \text { quartile 26.3-29.6 } \\
\mathrm{kg} / \mathrm{m}^{2}\end{array}$ & $\underset{\mathrm{m}^{2}}{4 \text { quartile }}>29.6 \mathrm{~kg} /$ \\
\hline Sample Size & 220 & 222 & 228 & 223 \\
\hline Age (yrs \pm S.D. $)$ & $78.2 \pm 6.1$ & $77.2 \pm 5.9$ & $76.7 \pm 5.4^{*}$ & $76.0 \pm 4.9^{*}$ \\
\hline Women (n, \%) & $150(68.2)$ & $126(56.8)^{*}$ & $159(69.7)$ & $182(81.6)^{* * *}$ \\
\hline African American (n, \%) & $68(30.9)$ & $58(26.1)$ & $68(29.8)$ & $90(40.4)^{* *}$ \\
\hline Hispanic (n, \%) & $91(41.4)$ & $105(47.3)$ & $111(48.7)$ & $97(43.5)$ \\
\hline White $(n, \%)$ & $61(27.7)$ & $59(26.6)$ & $49(21.5)$ & $36(16.1)^{* *}$ \\
\hline Education (yrs \pm S.D.) & $8.7 \pm 4.7$ & $9.0 \pm 4.7$ & $8.9 \pm 4.4$ & $8.6 \pm 4.5$ \\
\hline APOE- $\varepsilon 4(n, \%)$ & $70(32.7)$ & $50(23.2)$ & $67(29.7)$ & $58(26.1)$ \\
\hline Hypertension (n, \%) & $113(51.4)$ & $118(53.2)$ & $142(62.3)^{* *}$ & $159(71.3)$ \\
\hline Diabetes $(n, \%)$ & $25(11.4)$ & $39(17.7)^{*}$ & $48(21.1)^{* *}$ & $53(23.8)^{* *}$ \\
\hline LDL (mg/dl) & $120 \pm 38.1$ & $118 \pm 32.2$ & $122.7 \pm 35.2$ & $122.2 \pm 34.2$ \\
\hline Current smoker $(n, \%)$ & 43 (19.6) & $20(9.0)^{* *}$ & $19(8.3)^{* *}$ & $19(8.5)^{* *}$ \\
\hline Heart Disease (n, \%) & $48(21.8)$ & $52(23.4)$ & $59(25.9)$ & $72(32.3)^{*}$ \\
\hline Stroke $(\mathbf{n}, \%)$ & $29(13.2)$ & $16(7.2)^{*}$ & $33(14.5)$ & $25(11.2)$ \\
\hline
\end{tabular}

\footnotetext{
p $<0.05$

** $\mathrm{p}<0.01$

$* * *$

$\mathrm{p}<0.001$
} 
